\title{
A utilização de um Jogo Sério em aulas introdutórias à Educação Financeira
}

\author{
Camila Peres, IFRS, cmlperes@gmail.com \\ Evandro Manara Miletto, IFRS, evandro.miletto@poa.ifrs.edu.br \\ Johnata Souza Santicioli, IFRS, johnata.santicioli@gmail.com \\ Willian Chimura, IFRS, chimura.willian@gmail.com \\ Silvia Bertagnolli, IFRS, silvia.bertagnolli@poa.ifrs.edu.br
}

\begin{abstract}
Resumo: Este artigo explora a utilização a utilização de Jogos Sérios como material de apoio pedagógico em aulas introdutórias à Educação Financeira, com o intuito de contribuir com a aprendizagem de conceitos introdutórios, voltada para estudantes adultos. Durante o desenvolvimento do jogo foram considerados estes conceitos relevantes, de forma a refleti-los no ambiente do jogo. $\mathrm{O}$ jogo foi aplicado em uma aula composta por três etapas: uma breve explanação teórica sobre Educação Financeira, uma explicação sobre o funcionamento e as regras do jogo, bem como o uso deste pelos estudantes, e a aplicação de um questionário para validar a contribuição do jogo como material pedagógico, incluindo aspectos técnicos relacionados a ele. Concluiu-se que o jogo cumpriu com sua meta de favorecer a aprendizagem dos conceitos propostos.
\end{abstract}

Palavras-chave: Educação Financeira. Finanças Pessoal e Familiar. Jogos Sérios. Tecnologia Educacional.

\section{The use of a serious game in introductory financial education classes}

\begin{abstract}
This paper explores the use of Serious Games as pedagogical support material in Financial Education introductory classes, with the purpose of contributing to the learning and Financial Education of adult students. During the development game development, concepts relevant of Financial Education were explored. The game was applied in a class divided into three stages: a brief theoretical explanation about Financial Education followed by an explanation of the game rules and the actual playing followed by the application of a questionnaire in order to validate the contribution of the developed game as pedagogical material as well as the quality of the technical aspects of the game. Through the questionnaire it was concluded that the game fulfilled with its goal of contributing to the best learning of the proposed concepts.
\end{abstract}

Keywords: Educational Technology. Financial Education. Personal and Family Finance. Serious Game.

\section{INTRODUÇÃO}

É notório que a Educação Financeira é essencial para o bem-estar, equilíbrio e a manutenção de uma vida tranquila. Saber lidar com dinheiro e realizar uma boa administração financeira influencia diretamente na qualidade de vida das pessoas, por isso, essa área de conhecimento tem ganhado grande importância dentro das famílias. $\mathrm{O}$ número de inadimplentes, mudanças econômicas, tecnológicas, sociais e governamentais indicam a necessidade de educar financeiramente a população. Por exemplo, uma pesquisa realizada pelo Serviço de Proteção ao Crédito (SPC) e a Confederação Nacional de Dirigentes Lojistas (CNDL) concluiu que "em maio de 2018, o número de brasileiros negativados chegou a 63,29 milhões, o que representa 41,4\% da população adulta." (SPC-CNDL, 2018). Isso significa que mais de $40 \%$ da população adulta brasileira não consegue arcar com suas dívidas e em algum momento têm seus nomes cadastrados em listas de inadimplentes, o que ocorre por diversos motivos, em RENOTE 
especial pela falta de conhecimento sobre finanças. Por esse motivo, a Educação Financeira tem recebido incentivo de pessoas, governos, empresas e entidades em diversos países do mundo na disseminação de seus conteúdos.

O Mapeamento de Iniciativas de Educação Financeira realizado pela Estratégia Nacional de Educação Financeira (ENEF) no Brasil indica que apenas 5\% das iniciativas foram construídas utilizando jogos (ENEF, 2018). Existem Jogos Sérios voltados para Educação Financeira, contudo normalmente são jogos de perguntas e respostas que não têm relação nenhuma com situações práticas e reais ou são jogos direcionados ao público infantil (Junior et al., 2015).

Considerando o contexto exposto, o presente trabalho tem como principal objetivo investigar se o uso de um Jogo Sério, voltado para adultos, pode ser utilizado como apoio pedagógico no ensino de conceitos introdutórios em uma aula presencial de educação financeira. Resumidamente, o jogo ocorre todo em um único cenário onde o jogador deve utilizar-se de dois conceitos básicos da Educação Financeira (Consumo Consciente e Planejamento Orçamentário) para obter sucesso durante o desafio.

$\mathrm{O}$ artigo está organizado em cinco seções. Na seção 2 descreve brevemente o referencial teórico sobre Educação Financeira e Jogos, apresentando os aspectos relevantes e relacionados ao presente trabalho; a seção 3 descreve os procedimentos metodológicos utilizados, através da descrição das etapas do trabalho, dos métodos, materiais e técnicas empregados ao longo da pesquisa; a seção 4 detalha alguns dos resultados iniciais obtidos com a pesquisa; e, por fim, a seção 5 apresenta as conclusões baseada nos objetivos, hipóteses e resultados do trabalho.

\section{PRESSUPOSTOS TEÓRICOS}

O referencial teórico deste artigo encontra-se organizado em duas seções. A primeira aborda os tópicos sobre Educação Financeira e a segunda apresenta algumas considerações pertinentes sobre os conceitos relacionados a Jogos Sérios.

\subsection{Educação Financeira}

Analisando a literatura pertinente à área de Educação Financeira foi possível elencar os assuntos que são abordados com maior frequência: Relação com o dinheiro (desejos $\mathrm{x}$ necessidades), consumo consciente, planejamento orçamentário, crédito $\mathrm{e}$ dívidas, investimentos e riscos, seguros e previdência. Embora todos os temas sejam importantes, apenas Consumo Consciente e Planejamento Orçamentário foram selecionados para serem explorados no presente trabalho, pois são conceitos introdutórios para a educação financeira de qualquer cidadão.

\subsubsection{Consumo Consciente}

Segundo Buaes, Comerlato e Doll (2015) "entre o sonho de ter e a possibilidade de comprar é possível planejar o consumo. Esse é chamado de consumo consciente ou consumo planejado". Em outras palavras, o consumo consciente financeiro compreende a utilização dos recursos de forma planejada, com planos e prazos bem definidos para evitar gastos desnecessários ou desperdício de recursos.

Contudo, diversas estratégias de vendas são utilizadas para estimular o consumidor a realizar gastos não planejados, tais estímulos são chamados de Gatilhos Mentais. O psicólogo Kahneman (2012) sugere que o ser humano possui duas formas distintas para planejar e executar as ações: o Pensamento Rápido e o Pensamento Lento. O primeiro é emocional, intuitivo, impulsivo, involuntário e valoriza o presente, enquanto o segundo é racional, dedutivo, lento, consciente e valoriza o futuro. 
Estratégias de vendas utilizam Gatilhos Mentais para estimular a compra, visando se aproveitar do Pensamento Rápido. Segundo Cialdini (2012), o Gatilho da Escassez ocorre no momento em que um produto possui poucas unidades de venda, enquanto o Gatilho da Urgência sucede quando a oportunidade de obter um produto é limitado por um tempo - ambos exploram a aversão à perda do ser humano. Através desses gatilhos, clientes são estimulados a adquirir produtos ou serviços, sem perceber a importância de planejar o consumo, através do Planejamento Orçamentário. Dentre os diversos gatilhos existentes, no jogo objeto de estudo neste texto, são explorados o Gatilho de Escassez e o Gatilho de Urgência, pois são comumente utilizados em estratégias de vendas.

\subsubsection{Planejamento Orçamentário}

Cerbasi (2015) afirma que o Planejamento Orçamentário, ou simplesmente orçamento, é uma ferramenta para elaborar planos financeiros (pessoal ou familiar), o qual é utilizado para decidir quais serão as prioridades de consumo pessoal ou familiar onde deve constar todas as receitas fixas e variáveis (entrada monetária), despesas fixas e variáveis (saída monetária). Segundo argumentam Buaes, Comerlato e Doll (2015) é através do orçamento que é possível planejar como o dinheiro será gasto, aplicado, economizado e até mesmo investido. Basicamente, o planejamento deve ser mensal, de modo que seja possível "fazer o balanço do mês, para saber quanto sobra, quanto falta ou se há equilíbrio entre ganhos e gastos". Os mesmos autores definem as etapas do Planejamento Orçamentário, a seguir: anotação e separação das despesas por categoria; identificação das despesas fixas, variáveis e extras; planejamento do mês subsequente com base nas despesas do mês corrente.

\subsection{Jogos Sérios}

Jogos Sérios são desenvolvidos para serem cativantes ao mesmo tempo em que se propõem a alcançar algum objetivo pedagógico. Eles buscam causar um impacto nos seus jogadores, aprimorando sua experiência de aprendizagem e, portanto, devem ser tão atrativos quanto jogos de entretenimento enquanto ensinam (Bellotti et al., 2013). Existem pesquisas que descrevem os efeitos positivos da utilização de jogos na sala de aula. Embora seja possível encontrar críticas em relação aos métodos de avaliação do impacto de jogos na aprendizagem, Boyle et al (2016) identificaram 143 artigos classificados como de qualidade superior que reuniram evidências empíricas que jogos digitais ou tradicionais de fato contribuem para a aquisição de conhecimento e outras habilidades. Acredita-se que buscar novas formas de transmitir o conhecimento em sala de aula se torna relevante quando se considera que os novos meios de interação que surgem influenciam as formas de pensar e, consequentemente, os estilos de aprendizagem dos estudantes (Prensky, 2012). Dessa forma, as próprias características motivacionais e engajantes que o jogo possui se tornam relevantes para justificar sua aplicação em sala de aula. Segundo Piccini (2008),

A melhor forma de ensinar através de jogos é, então, fazer com que suas regras sejam semelhantes ao que o jogador precisa aprender e não forçando o jogador a aprender um jogo para ir sendo "informado" do conteúdo. Em outras palavras, é mais coerente que um jogo que se proponha a ensinar matemática estimule o jogador a solucionar problemas de soma, subtração, divisão e multiplicação ao invés de obrigar o jogador a aprender a controlar uma personagem que percorre um labirinto resgatando algarismos e sinais de operações aritméticas. (Piccini, 2008, p.26) 
Jogos são compostos de regras, que definem as ações permitidas ao jogador e as consequências que elas terão dentro do sistema apresentado. Para que a aquisição e a compreensão do conteúdo ocorram é necessário que ele esteja entrelaçado nessas regras que compõem a base do jogo, de forma que, somente ao dominar os conhecimentos que se busca ensinar, o jogador seja capaz de manipular o sistema a seu favor. Portanto, o desenvolvimento de um jogo sério deve considerar o assunto que será ensinado como base para a criação do sistema de regras, buscando na teoria a ser ensinada as ações e consequências que aparecerão ao longo do jogo (Piccini, 2008). Dessa forma, para alcançarem o seu potencial, é importante que Jogos Sérios sejam desenvolvidos de forma a pensar no conteúdo que pretendem ensinar e aplicados utilizando-se planos de aula planejados para a sua aplicação (Fortuna, 2000).

\section{MATERIAIS E MÉTODOS}

As informações sobre os materiais e métodos utilizados na produção deste artigo foram organizadas em três seções. A primeira aborda a metodologia utilizada, a pesquisa-ação; a segunda descreve o jogo, explicitando seus elementos e interações; e a terceira seção descreve brevemente o método MEEGA+, utilizado na avaliação do jogo.

\subsection{Metodologia de Pesquisa}

Esta pesquisa é exploratória, caracterizada pela busca de um maior conhecimento sobre a aplicação de jogos digitais no ensino de Educação Financeira. Ela se encaixa no método de pesquisa-ação educacional, pois "utiliza técnicas de pesquisa consagradas para informar a ação que se decide tomar para melhorar a prática" (Tripp, 2005). Seu objetivo é duplo - considerando a busca de conhecimento científico validado e a intervenção em determinadas situações, buscando solucionar algum problema identificado em determinado ambiente. Nesta metodologia, a teoria fundamenta as práticas que serão aplicadas, enquanto a prática permite a coleta de dados. Juntas, a teoria e a prática geram reflexões que permitem ampliar o conhecimento científico, característica essencial da pesquisa-ação (Filippo et al, 2019).

A pesquisa partiu das teorias de ensino de Educação Financeira e de desenvolvimento de Jogos Sérios para favorecer o planejamento de uma proposta de ensino que misturasse características de uma aula expositiva, mas que utilizasse o jogo como uma ferramenta pedagógica, com vistas a promover a aprendizagem. Para ser produtivo em sala de aula, atingir seus propósitos engajantes e de aprendizagem, o jogo sério deve estar inserido em um planejamento (Fortuna, 2000). Dessa forma, elaborou-se uma aula introdutória à Educação Financeira, foram abordados os conceitos de Consumo Consciente juntamente com diversos Gatilhos Mentais envolvidos nas técnicas de venda e de Planejamento Orçamentário. O planejamento da aula incluiu um jogo digital desenvolvido de forma a complementar os conhecimentos que foram abordados na aula teórica, de maneira simulada.

Por ser uma pesquisa-ação com objetivos exploratórios, a coleta de dados ocorreu durante uma atividade prática. Foi ministrada uma aula introdutória sobre Educação Financeira, apresentando conceitos básicos para uma turma de treze estudantes adultos, com diferentes perfis de frequência de utilização de jogos digitais e de tecnologias. Apesar do jogo ter sido desenvolvido de forma a executar em dispositivos móveis, o jogo foi instalado em computadores com o sistema operacional Windows disponíveis no laboratório por serem dispositivos mais familiares aos estudantes. Durante esta aula foi proposta a atividade envolvendo o jogo sério 
desenvolvido para este trabalho, a maioria dos estudantes jogou em pares, de forma a apenas um deles ser o jogador controlador (que toma as ações) na maioria dos casos.

\subsection{O Jogo}

O jogo sério abordou os conceitos de Consumo Consciente e de Planejamento Orçamentário. Em seu desenvolvimento, buscou-se criar o um ambiente que incentiva o Pensamento Rápido - uma resposta automática, instantânea e, na maioria dos casos, inadequada. Para ensinar a importância da utilização do Pensamento Lento, o sucesso do jogador só seria possível caso fosse utilizado este tipo de pensamento, ainda que de maneira um pouco relutante, já que ele exige maior reflexão e toma mais tempo. Esperava-se que os jogadores compreendessem de forma prática a importância do consumo consciente, uma vez que o jogo o submete à diversas situações envolvendo Gatilhos Mentais a fim de desafiá-lo a lidar com seu Pensamento Rápido.

Considerando a importância da Educação Financeira e a potencialidade de um ensino dinâmico que os jogos apresentam, o jogo produzido nesta pesquisa foi pensado de forma que a experiência do estudante complementasse e fixasse os conceitos apresentados na aula de Educação Financeira. Os conceitos de Pensamento Rápido e Pensamento Lento foram apresentados durante a aula e trabalhados na temática e mecânicas do jogo. O jogador deveria tomar decisões rápidas, associadas ao conceito de Pensamento Rápido, mas sempre considerando a relação custo-benefício, que exige o Pensamento Lento, para alcançar a melhor pontuação possível.

Para ir além dos diferentes tipos de pensamento e explorar o conceito de Planejamento Orçamentário, assim como sua importância através do jogo, a mecânica do jogo parte da simulação do recebimento de um salário que deve ser dividido em três necessidades: conforto, alimentação e saúde. Por exemplo, na Figura 1, o salário do jogador é dois mil e seiscentos reais e ele deve dividi-lo entre as três necessidades consideradas como relevantes e para o período de um mês. Ainda considerando este exemplo, que corresponde ao mês de março, para a primeira necessidade (conforto) foi associado o valor de cem reais, para a segunda necessidade (alimentação) o valor de trezentos reais e para a terceira (saúde) não foi atribuído valor. O jogador não pode iniciar o jogo enquanto todo o valor do salário não for distribuído entre as necessidades definidas. Observa-se que nesse nível do jogo o conceito de "Investimentos" ainda não é abordado. A mecânica do nível 1 prioriza a organização de um planejamento orçamentário, para depois realizar um consumo consciente.

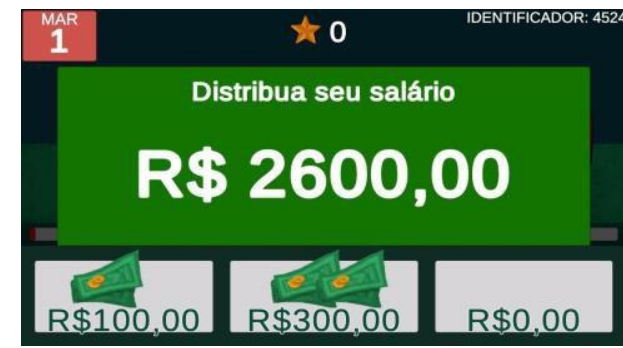

Figura 1 - Tela de distribuição do salário

Fonte: Dos autores

Ao longo de "um mês" dentro do jogo, que dura aproximadamente 1 minuto, o jogador deve equilibrar suas necessidades, escolhendo quais produtos comprar e quais ignorar, considerando o custo-benefício e seu planejamento inicial. A Figura 2 (a) apresenta uma das telas do jogo, onde o jogador irá passar a maior parte do tempo. Nela 
tem-se três "prédios", um azul que representa um shopping, relacionado à "necessidade de conforto", um na cor laranja, que corresponde a um supermercado "necessidade de comida" e um rosa, que representa uma farmácia, ou a "necessidade de remédios". Cada uma dessas construções oferece produtos relativos ao que representam e também possuem barras vermelhas que indicam ao jogador a necessidade de consumir produtos de acordo com sua categoria. Essas barras vermelhas iniciam preenchidas, sendo que seu preenchimento se esgota conforme o tempo do jogo. Abaixo de cada uma das barras encontra-se a quantidade de dinheiro distribuída no começo de cada mês do jogo. Os produtos oferecidos podem ser comprados pelo jogador, sendo que cabe a ele a decisão de comprar ou não. Para efetuar a compra o jogador deve analisar o planejamento orçamentário realizado e analisar se o item é necessário e se é viável a sua aquisição. Cada produto possui diferentes níveis de qualidade, representados por estrelas, e diferentes preços, representados por cifrões, cada um equivalente a cem reais. Quanto maior a qualidade do produto, mais ele supre da necessidade de consumo, aumentando o preenchimento da barra vermelha que indica necessidade.

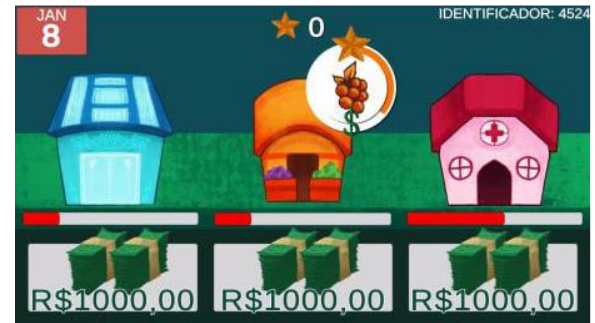

(a)

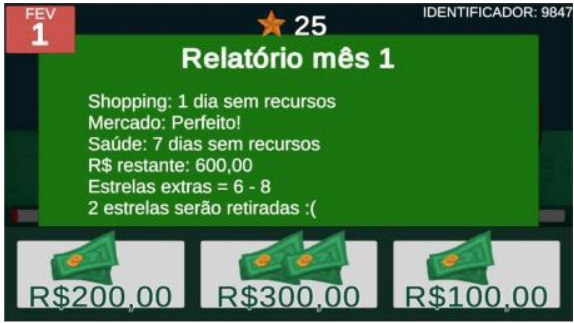

(b)

Figura 2 - Tela do jogo com construções (a) e relatório do mês (b)

Fonte: Dos autores

Por exemplo, a Figura 2 (a) ilustra junto ao prédio do supermercado um item que pode ser adquirido, que tem qualidade nível 1, pois tem uma estrela, e o preço é cem reais. Cada item comprado faz com que o orçamento planejado sofra alterações, diminuindo os recursos para a aquisição de itens de uma mesma categoria. Os produtos ficam disponíveis para compra por um determinado tempo (uso dos Gatilhos Mentais), para então desaparecer e eventualmente serem substituídos por novos, com diferentes qualidades e preços. Acima das construções existe um contador de estrelas, referentes a qualidade do produto. Ao comprar produtos de maior qualidade essa pontuação aumenta e, ao esvaziar completamente a barra, sem cumprir com as necessidades de consumo, a pontuação diminui. Cabe ao jogador escolher quais produtos comprar, baseando-se em seu planejamento inicial, preço, qualidade e necessidade. Ao esgotar os recursos destinados para determinada necessidade, o jogador precisa esperar até o mês seguinte para repensar sua estratégia.

Observa-se que ao término de cada mês o jogador recebe um relatório detalhando as necessidades que foram atendidas ou não e sua pontuação obtida com o término do mês (Figura 2 (b)). Dessa forma, o jogo possibilita aos estudantes a possibilidade de testar os conhecimentos teóricos em uma simulação simples, podendo ver as consequências de suas ações de consumo. 


\subsection{A Avaliação}

Várias pesquisas demonstram a potencialidade que os Jogos Sérios possuem para o ensino dos mais diversos conceitos, em diversas áreas do conhecimento. Para se entender o real impacto causado pelos jogos desenvolvidos é necessário que eles sejam devidamente avaliados (Petri, 2017). A avaliação permite identificar os sucessos e falhas do jogo, se ele atingiu os objetivos definidos no seu planejamento, assim como indicar melhorias para a evolução do mesmo (Branch, 2010).

Para avaliar a experiência do jogador e sua percepção de aprendizagem após a utilização do Jogo Sério desenvolvido, foi aplicado um questionário baseado no método avaliativo MEEGA+ (Model for Evaluating Educational Games). O método MEEGA+ é focado em avaliar a qualidade do jogo principalmente nos quesitos que envolvem a percepção do jogador sobre sua usabilidade e experiência (Petri, 2017), através da aplicação de questionários. A análise se dá através de perguntas sobre a experiência subjetiva do jogador, permitindo a coleta de dados sobre aspectos como o foco da atenção, diversão, desafio, interações sociais, relevância, satisfação, usabilidade e percepção de aprendizagem (Petri, 2017), o questionário também apresenta uma seção para relatar pontos fortes, fracos e comentários adicionais. Este método também busca agir de forma rápida e não intrusiva para maior efetividade em avaliar a qualidade dos jogos. Esperava-se que, ao refletir sobre os dados coletados, fosse possível chegar a conclusões sobre a potencialidade do jogo possibilitar a aquisição do conhecimento relativo aos conteúdos abordados, assim como a percepção dos jogadores sobre o que deve ser melhorado.

\section{RESULTADOS E DISCUSSÃO}

A aplicação do questionário foi realizada logo após a experimentação dos estudantes com o jogo. Obteve-se 13 questionários respondidos para a avaliação do Jogo Sério proposto e seu potencial para aprendizagem. As perguntas do questionário, assim como os dados coletados são apresentados em forma de gráfico nas Figuras 3 e 4 .

Os resultados acerca da experiência do jogador (Figura 3) revelam que um dos maiores aspectos a serem considerados a se evoluir no jogo que foi desenvolvido estão relacionados ao desafio e à captação da atenção dos jogadores, o que fundamenta a hipótese de que a falta de uma progressão de desafios mais adequada pode ter impedido um maior engajamento por parte dos estudantes. Uma possível interpretação destas informações sugere que a atenção dos jogadores reduziu à medida que aprenderam a utilizar do Pensamento Lento, o que pode ter ocorrido rapidamente, tornando o restante do jogo pouco desafiador para alguns estudantes. 


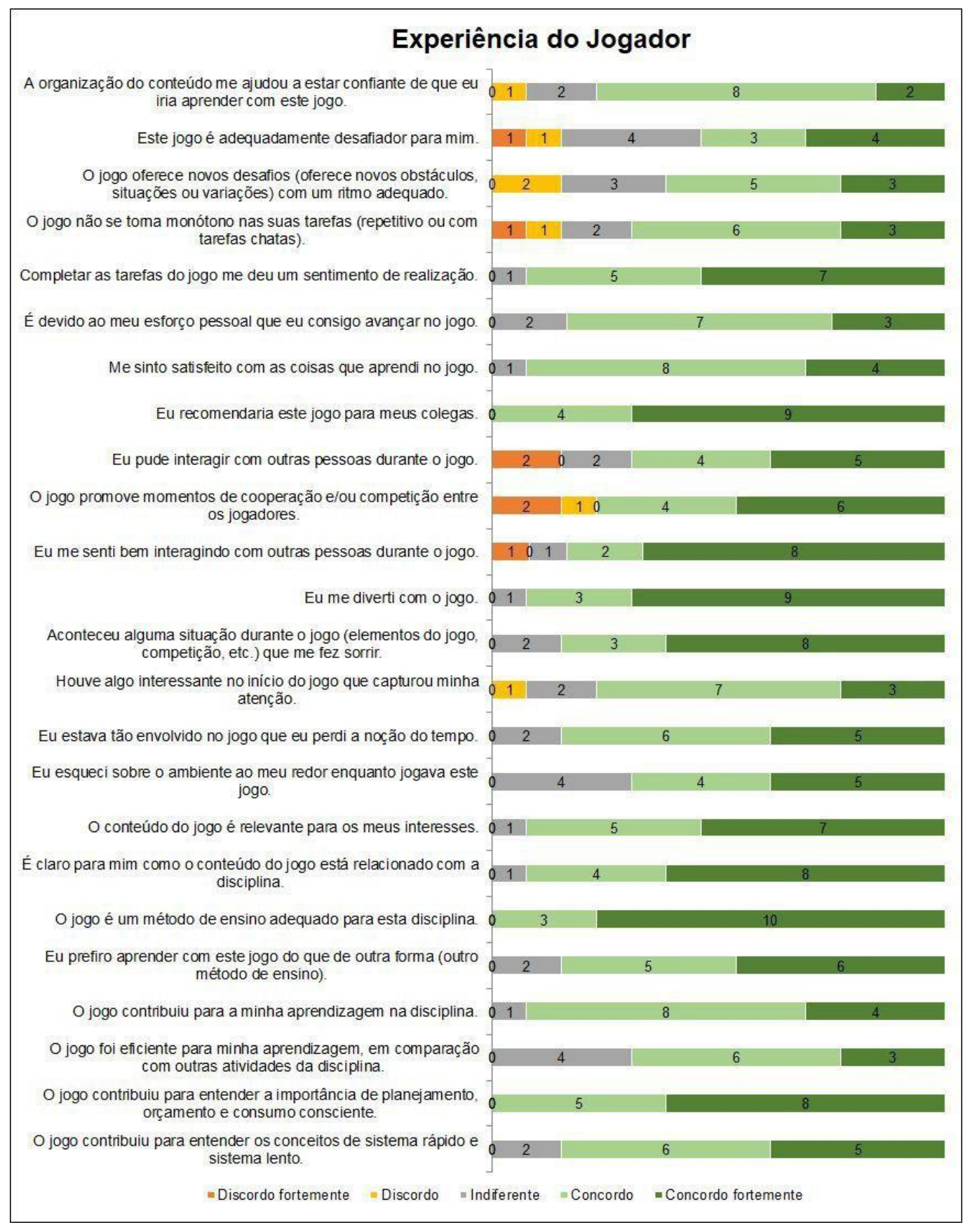

Figura 3 - Experiência dos jogadores

Fonte: Dos autores. Adaptado de Petri (2017)

Quanto às características de usabilidade avaliadas, a maioria dos jogadores o avaliou positivamente em diversos quesitos, sendo as características melhores avaliadas relacionadas a estética e acessibilidade. Visando uma melhor usabilidade, as mecânicas do jogo e a disposição dos elementos visuais foram pensadas de forma a serem familiar para jogadores que estão acostumados com dispositivos móveis; entretanto, esta avaliação deve ser interpretada de forma cautelosa, uma vez que as regras e objetivos do jogo foram apresentados ao longo da aula, antes de sua aplicação. Para maior fidedignidade, seria necessário uma aplicação do jogo sem introdução prévia em aula.

Os resultados obtidos com as questões "É claro para mim como o conteúdo do jogo está relacionado com a disciplina" e "O jogo é um método de ensino adequado 
para esta disciplina" apontam que, mesmo tratando-se de um público composto por estudantes adultos, o uso de jogos pode favorecer o engajamento e que os estudantes perceberam os conteúdos da disciplina nas mecânicas adotadas pelo jogo desenvolvido.

As respostas coletadas nas quatro últimas questões do questionário sobre experiência (Figura 3), relacionadas diretamente à aprendizagem percebida dos conceitos abordados em aula, sugerem que o jogo atingiu seu objetivo de contribuir como apoio pedagógico para aprendizagem dos conceitos de Educação Financeira, uma vez que a grande maioria dos jogadores responderam concordar e concordar fortemente.

$\mathrm{O}$ design do jogo foi definido tendo em vista que ele seria aplicado em uma turma de estudantes adultos. Considerando as avaliações referentes à estética, que obtiveram a maior mediana possível nos dois quesitos avaliados (design atraente e consistência de cores, textos e fontes), e também com base de oito relatos de jogadores que citaram elementos gráficos como ponto forte, é seguro inferir que o design do jogo foi atraente para os estudantes, possivelmente tendo sido a característica de maior relevância para garantir sua boa usabilidade (Figura 4).

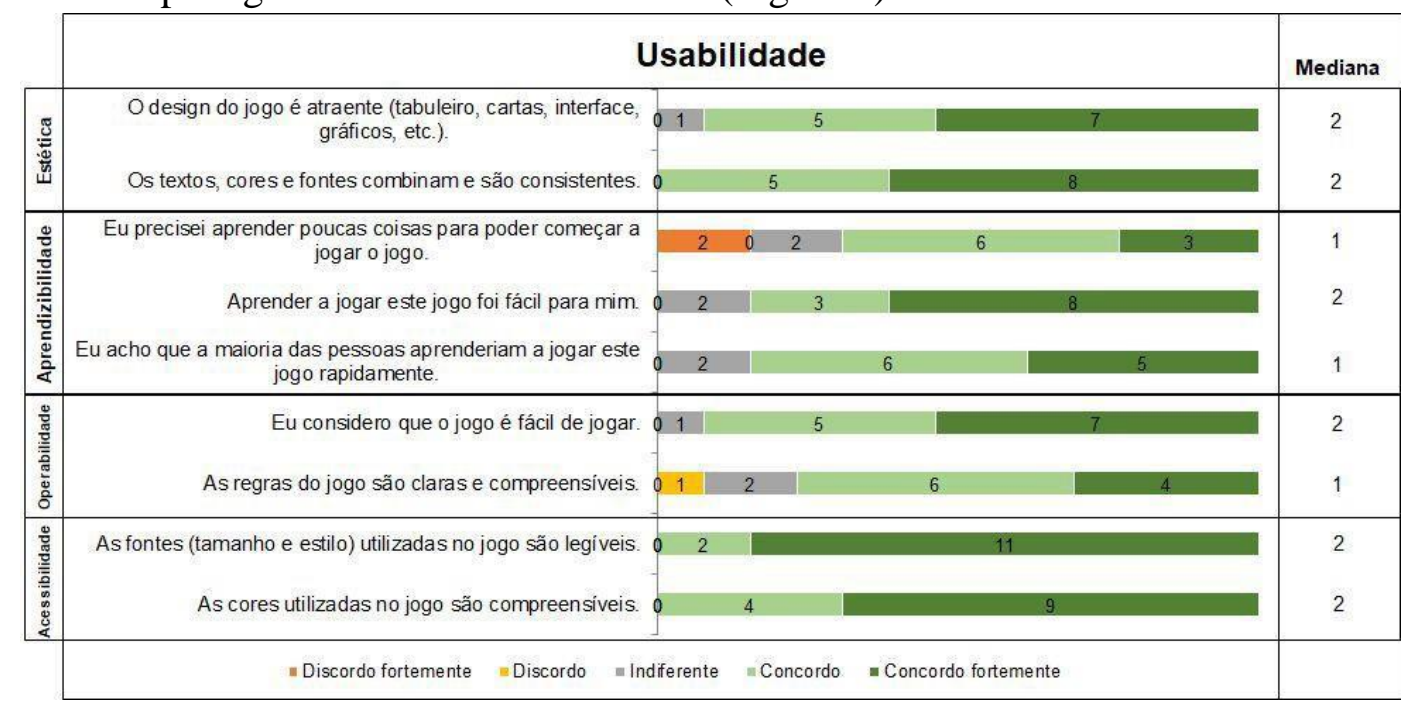

Figura 4 - Usabilidade do jogo

Fonte: Dos autores. Adaptado de Petri (2017)

Nas seções de pontos fortes, fracos e comentários adicionais do questionário, cinco relatos foram feitos acerca da rapidez e da necessidade de raciocinar para jogar como pontos fortes. Tendo em vista que a ideia norteadora era produzir um ambiente onde o jogador precisasse lidar com o Pensamento Rápido e Pensamento Lento a fim de obter mais recompensas, estes relatos sugerem que a ideia foi adequadamente expressa e percebida pelos jogadores.

\section{CONCLUSÕES}

Jogos Sérios estão associados a diversos efeitos positivos e contribuem com a aprendizagem. Foi possível observar a relação dos conceitos de Pensamento Lento e Rápido com a percepção dos jogadores sobre as tomadas de decisão necessárias para concluir as tarefas do jogo. A realização de toda pesquisa sob os conceitos metodológicos de uma pesquisa-ação foi pertinente, pois foi possível observar o comportamento dos estudantes durante o uso do jogo e analisar, a partir dos comentários, quais novos elementos poderiam ser incluídos e abordados no jogo. 


\section{REFERÊNCIAS}

BELLOTTI, F.; KAPRALOS, B.; LEE, K.; MORENO-GER, P.; BERTA, R., Assessment in and of Serious Games: An Overview, Hindawi Advances in Human-Computer Interaction, London, fev. 2013. Disponível em: https://www.hindawi.com/journals/ahci/2013/136864/. Acesso em: 20 mai. 2019.

BOYLE, E. A; HAINEY, T.; CONNOLLY, T.; GRAY, G.; EARP, J.; OTT, M.; LIM, T.; NINAUS, M.; RIBEIRO, C.; PEREIRA, J. . An update to the systematic literature review of empirical evidence of the impacts and outcomes of computer games and serious games. Computers and Education 94, 178-192, Amsterdam, mar. 2016.

BRANCH, R. M. Instructional Design: The ADDIE Approach. New York: Springer. 2010. 216p.

BUAES, C. S.; COMERLATO, D.; DOLL, J. Caderno de Educação Financeira: viver bem com o dinheiro que se tem. Porto Alegre: UFRGS. 2015. 45p.

CERBASI, G. P. Como Organizar sua Vida Financeira. Rio de Janeiro: Sextante, 2015. 160p.

CIALDINI, R. B. As Armas da Persuasão: como influenciar e não se deixar influenciar. Rio de Janeiro: Sextante, 2012. 304p.

ENEF. Estratégia Nacional de Educação Financeira. 2010. Apresentação do Mapeamento Nacional das Iniciativas de Educação Financeira no Brasil. Disponível em: <http://www.vidaedinheiro.gov.br/2-mapeamento/>. Acesso em: 20 out. 2018.

FILIPPO, D.; ROQUE, G.; PEDROSA, S. Pesquisa-ação: possibilidades para a Informática Educativa. In: Informática na Educação: Abordagem Qualitativa de Pesquisa (Volume 3). Porto Alegre: SBC, 2019. p.1-29. (Série Metodologia de Pesquisa em Informática na Educação, 3).

FORTUNA, T. R. Sala de aula é lugar de brincar? In: XAVIER, M. L. M.; DALLA ZEN, M. I. H. (Org.) Planejamento em destaque: análises menos convencionais. Porto Alegre: Mediação, 2000. p.147-164. (Cadernos de Educação Básica, 6).

JUNIOR, R. C. T.; TRASPADINI, A. T.; SANT'ANA, V. A.; NASCIMENTO, D. B.; Nunes, V. B.; Nobre, I. A. M. Finance Game: Um Jogo de Apoio à Educação Financeira. RENOTE, Porto Alegre, v. 13, n. 1. 2015.

KAHNEMAN, D. Rápido e Devagar: duas formas de pensar. Rio de Janeiro: Objetiva, 2012. 608p.

PETRI, G.; GRESSE, W. C.; BORGATTO, A. F. MEEGA+, Systematic Model to Evaluate Educational Games. Encyclopedia of Computer Graphics and Games, 1-7. doi:10.1007/978-3-319-08234-9_214-1, Los Angeles, USA, dez. 2017

PETRI, G.; GRESSE, W. C. How games for computing education are evaluated? A systematic literature review. Computers \& Education, 107, 68-90, Amsterdam, abri. 2017.

PICCINI, Maurício da Silveira. Por uma teoria das supercordas da narrativa. Porto Alegre: Faculdade de Letras, PUCRS, 2008. Dissertação de Mestrado.

PRENSKY, M. Aprendizagem baseada em jogos digitais. São Paulo: Senac, 2012. p 576.

SPC-CNDL. Indicadores Econômicos SPC Brasil e CNDL, 2018. Disponível em: $<$ https://www.spcbrasil.org.br/wpimprensa/wp-content/uploads/2018/06/Análise-PF_ma io_2018-1.pdf>. Acesso em: 04 nov. 2018.

TRIPP, D. Pesquisa-ação: uma introdução metodológica. Educação e Pesquisa, São Paulo. v.31, n.3, p. 443-466, 2005. 